\title{
Autohydrolysis of Annona cherimola Mill. seeds: Optimization, modeling and products characterization
}

\author{
P.C. Branco ${ }^{\mathrm{a}, \mathrm{b}, 1}$, A.M. Dionísio $^{\mathrm{a}, 1}{ }$ I. Torrado $^{\mathrm{a}}$, F. Carvalheiro ${ }^{\mathrm{a}}$, P.C. Castilho ${ }^{\mathrm{b}}$, L.C. Duarte $^{\mathrm{a}, *}$ \\ a Unidade de Bioenergia, LNEG - Laboratório Nacional de Energia e Geologia, Estrada do Paço do Lumiar 22, 1649-038 Lisboa, Portugal

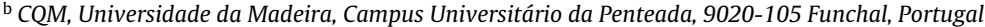

\section{A R T I C L E I N F}

\section{Article history:}

Received 31 January 2015

Received in revised form 9 June 2015

Accepted 12 June 2015

Available online 23 June 2015

\section{Keywords:}

Biorefinery

Heterogeneous reaction

Kinetic parameters

Modeling

Optimization

Xylo-oligosaccharides

\begin{abstract}
A B S T R A C T
Annona cherimola Mill. seeds are a residue of the industrial processing of this fruit, for which, presently, there is no industrial application. They have a considerable amount of oil, which can be converted into biodiesel, but the remaining lignocellulosic fraction still needs relevant added-value valorization routes. In this work, the selective hemicelluloses removal by autohydrolysis was optimized aiming to maximize the yield of oligosaccharides with potential applications in food, pharmaceutical and cosmetic industries. A maximum of $10.4 \mathrm{~g} \mathrm{~L}^{-1}$ of oligosaccharides was obtained, for a severity factor of 3.6 , where $74.5 \%$ of the original hemicellulose was solubilized.

The process kinetics is presented, modeled (based on the Arrhenius equation) and its scale-up is discussed. The hydrolyzate shelf-life was evaluated and the produced oligosaccharides are stable at room temperature for, at least, 3 weeks. Furthermore, all oligosaccharides are also stable at $100{ }^{\circ} \mathrm{C}$ for $1 \mathrm{~h}$, in $\mathrm{pH}$ values between 1 and 11, enabling their industrial processing, and at $37^{\circ} \mathrm{C}$ for $3 \mathrm{~h}$, in pH values between 1 and 3, thus indicating its potential classification as non-digestible oligosaccharides. The remaining cellulose enriched solids presented an increased enzymatic digestibility (as a function of the autohydrolysis severity) that assures its efficient use in subsequent processes (e.g., bioethanol production).

The upgrade route developed in this work in combination to the previously reported use of $A$. cherimola seed oil for biodiesel production can lead to an integrated zero-waste valorization strategy within the biorefinery framework.
\end{abstract}

(C) 2015 Elsevier B.V. All rights reserved.

\section{Introduction}

Annona cherimola Mill. seeds are the main residue of the industrial processing of cherimoya. Currently it has no significant use, being considered a waste disposable problem.

The seeds have a significant oil content (up to $30 \%$ ) that can be used for biodiesel production [1]. Cherimoya is produced mainly in Spain ( 3000 ha) and Chile ( 1000 ha), being common in the Andean region and in the Iberian countries. Moreover, Annonaceae are well spread all over the globe and cherimoya, being one of the most important species of this family, can maybe be considered a model for other Annonaceae.

Oil extraction yields a lignocellulosic fraction, the seed cake, which must be further upgraded. The presence of xyloglucans in

\footnotetext{
* Corresponding author.

E-mail address: luis.duarte@Ineg.pt (L.C. Duarte).

1 The authors wish it to be known that the first two authors should be regarded as joint first authors.
}

the seeds of another Annona species, namely A. muricata, has been reported [2], and hence the presence of these compounds is also expected in the lignocellulosic fraction of cherimoya seeds. This is a strong indication that this residue can be used to produce novel xylo-oligosaccharides (XOS), thus, assuring a potential valorization of cherimoya seeds within the biorefinery. In fact, oligosaccharides' (OS) demand has increased significantly and, thus, the search for new OS, and specifically of novel XOS sources is currently a relevant endeavor, as it can lead to novel products with applications in food, pharmaceutical and cosmetic industries [3,4].

The autohydrolysis process is considered to be the most appropriate choice $[3,4]$ for the selective separation of hemicelluloses and the maximization of the OS production. This process has many significant advantages e.g., reduced production of monosaccharides [5], but the optimal operation conditions depend significantly from the composition of the feedstock.

There are several tools to help to better understand and control the behavior of the autohydrolysis process [6], namely the use of the severity factor $\left(\log R_{\mathrm{O}}-\mathrm{Eq}\right.$. (1)) and formal kinetic models. The severity factor, $R_{\mathrm{O}}$, was developed to compare steam explosion and 